\title{
Theoretical Exploration and Practice of the Funding for Educations in China
}

\author{
Huizhong Xu, Zhiqin Ben, Jie Deng \\ Nantong University, Nantong, China \\ Email: xhzh10906@ntu.edu.cn
}

Received 27 January 2014; revised 27 February 2014; accepted 4 March 2014

Copyright (C) 2014 by authors and Scientific Research Publishing Inc.

This work is licensed under the Creative Commons Attribution International License (CC BY). http://creativecommons.org/licenses/by/4.0/

c)

\begin{abstract}
Chinese current funding systems have basically solved the economic distress of poor students' right to receiving educations, but there are still many problems and shortcomings, such as the unclear funding concepts, the disjunction of the funding and education, low performance of the funding for education. From the capital theory, funding includes the three investment areas: cultural capital, human capital and social capital, which show us a new perspective to make clear the intrinsic link between the funding and education and provide a theoretical basis. Therefore, we can totally improve the performance of the funding for education through the three aspects: protecting cultural capital to meet the educational needs, enhancing human capital to meet the needs of self-development and accumulating social capital to meet the needs of the upward social mobility.
\end{abstract}

\section{Keywords}

Funding; Education; Performance; Capital

\section{Introduction}

With the constant improvement of university funding systems, China has basically solved the economic distress of poor students' right to receiving educations. In this process, people have gradually realized the positive significance of education funding. Some scholars and institutions presented research results and practices. However, it is also lacking in exploring on the internal theory linking between the funding and education and how to play this intrinsic link. Combining with the research of the capital theory, we have found that investment funding includes the three areas: cultural capital, human capital and social capital, which provide a new perspective and the starting point for our research. So in this paper, we will focus on the theoretical exploration and practice of the funding issue for educations in China and analyze the three methods and paths to promote the education performances. 


\section{The Status}

\subsection{Financial Aid: The Fundamental Guarantee and Prerequisite of Education}

1) In China, there are many laws and regulations and related documents to safeguard the poor students' right to receiving educations. According to the 37th provision in “The Educational Law of the PRC”, the State and society provide various assistance forms for the poor family children and teenagers who and meet the conditions of the access to schools. "CPC Central Committee and State Council on further strengthening and improving the ideological and political education” (No. 16, Central Files) also clearly states: that strengthening the funding work for poor college students, and constantly improving the funding policies and measures must be done to form a funding system, which is mainly composed of national student loans, also includes student scholarships, work-study funds, subsidy for special difficulties and tuition exemption, and helps the poor students complete their studies.

2) According to the various stages characteristics of the education, the government has developed appropriate funding ways and means. In compulsory education, China has implemented the "two exemptions and one subsidy” policy that all students exempt from tuition and fees, has eliminated the book-fees for the difficult family students, and has implemented the subsidy policy for boarders from difficult families. All vocational school students have received 1500 Yuan living subsidies per year in China. 20\% of senior middle school students have received 1500 Yuan subsidies per year in China. In universities, China has now basically formed a full-range student financial assistance system including scholarships, loans, part-time jobs, allowance and tuition exemption.

3) In China, the limitations of funding have been increasingly relaxed, funding efforts have been strengthened, and benefit coverage of funding has expanded. According to the statistics of the Ministry of Finance and the Ministry of Education, from 2010 to 2011, the national totally has funded almost 156,000,000 students in colleges and universities, vocational schools, senior middle schools, compulsory education schools. The amount of subsidy has come to almost 183,676,000,000 Yuan. The amount of students and money all has hit another historical high. The fund sum in 2011 has increased 30,870,000,000 Yuan, almost 45.6\% more than in 2009 (People Net, 2012). In the government work report, Premier Wen Jiabao has mentioned that "China has initially established a complete system of student financial assistance for economically disadvantaged families , effectively protected every student from dropping out of school because of family difficulties” (Wen, 2012) at the Fifth Plenary Session of the Eleventh National People’s Congress.

\subsection{Funding to Promote Education: Facing the Problems of the Concept and Practice}

\section{1) Lacking of Development Funding Concepts}

After years of exploration, China has formed a relatively complete system of funding. However, the system that bases on the existing non-reimbursable funding formula has weakened the value of the funding work. The work always pays more attention on the results whether subsidized funds or supplies have been distributed to the appropriate students' hands and solved the substance difficulties for students, while ignoring the education effects of the funding. "The phenomenon that funding has turned into the substance helping only is widely spreading. Then, for students, it is lacking of information penetration on the politics, morality and regulations. And it is also lacking of promoting on the physiology, psychology and personality.” (Zhao, 2012) Therefore, there is often such a situation: funding just is the processing that students apply for and get the money. But they do not know what the funding connotation is. And it is more impossible for students to internalize funding into the upward power. If things continue, it would indulge students' ideas of "reap without efforts" and consequences of “waiting, depending and asking for" because of enjoying usual free funding.

\section{2) Separating Funding from Education}

At present, some schools have begun to focus on the effect of funding on promoting education. But they always separate funding from education in actual operation. The education is only the generalized education. On other words, it will happen no matter whether the funding takes place. So such education is not the necessary meaning of funding. And if we draw a forced analogy on funding and education, it would cause students' resentment and hurt students' positive significance of funding. No.16 central document has shown clearly that strengthening and improving ideological and political education should combine solving ideological problems with solving practical problems. Thus, we have to regard funding as effective means of education, combine the 
substance help and spiritual help, avoid the merging difficulty phenomenon, and achieve that "funding, guided and oriented as education, would burden the educational function in order to attain the maximum benefits, and reflect the true value" (Cao \& Li, 2010).

\section{3) Scattered Funding Strength and Lacking of Cohesion}

Although China has basically formed the full range of college students financial aid system , but the overall strength of funding remained fragmented, failed to form the aggregate effect that " $1+1$ is greater than 2 ". It is mainly reflected on the following aspects. On the one hand, funding is lacking of the unified management. Although many universities have set up a special department to in charge of the funding for poor students, but, on the actual operation, some questions often emerge. Several departments are responsible for the different funded projects, so it sometimes causes the overlap or omission funding policies, over demand or under demand recipients. Then the impartiality and fairness of the funding are badly influenced. It is not conducive to maximizing the funding performance on the education. On the other hand, funding systems are lacking of optimized combination. Although the funding policies are served for poor students, but funded systems are closed. Each of the systems is carried out solely without compatibility with other systems, and fails to echo and care for each other. On the perspective of schools, it is difficult to form a certain funding guide on the education because of the absence of the reasonable and optimized combination in the limited amount. On the perspective of students, it is difficult to stimulate students' individual potential because of the absence of scientific assessment of the recipient models.

\section{The Inherent Logic between the Funding and the Education Performance Promoting}

Although the association exists in funding and education, but we should make it clear whether the association is an inevitable relationship. Whether the funding will inevitably lead to the emergence of the education effectiveness? Whether the effectiveness of educations must need the funding trigger or pushing? Therefore, we must carry out in-depth analysis of the funding to expose the inherent association between funding and education. Capital theory is an important research in the economics and the sociology. The funding is using economic means to help poor students receive educations. To some extent, it is the role that the capital plays in the educational process. So it also accords with the general law of capital theory. Then, the funding is the process that human capital, cultural capital and social capital are embodied and play a part in the education.

\subsection{The Institutionalization of Cultural Capital Affects the Sharing of the Educational Resources}

"Cultural capital refers to the tangible or intangible property related to any culture and cultural activities. It is not only the result of the currency investment, but also the result of the non-currency investment. The accumulation of cultural capital not only takes a certain time, but also needs to process in a concretization and somatization form, and pursuits more value. Expanding reproduction itself is its eternal motivation.” (Bourdieu, 1997) Cultural capital exists in three forms: a specific state, an objective state and an institutionalized state. In this paper, we mainly talk about the institutionalized state of cultural capital. It is the existing form of the culture capability, and it is authorized by the cultural system. It also can be said a label, such as diploma and degree certificates. With the thorough implementation of the college and university education fees, the investment of the economy has become an important prerequisite for students to accept the institutional cultural capital. For example, when poor students are making a choice during the College and University Entrance Examination decision, they would tend to choose going to higher schools as the first principle because they cannot burden the responsibility of losing the learning opportunities in colleges or universities for the choosing mistakes. Thus, they would lose much more opportunities to come into the higher schools or professions which have stronger competition, better education resources and higher education fees. It would result in reducing the "gold content" of a diploma. So, compared to non-poor students, poor students would be at a disadvantaged position in gaining the quantity and quality of the institutionalized cultural capital because of the economic investment.

With the implementation of student loans, national tuition assistance, the green channels and tuition exemption, it has broken economic hardship for poor students, and enhanced their expectations and abilities to gain the institutionalized cultural capital. To some extent, the constraint of the family economic status has been broken for pursuing cultural capital. They may have more opportunities to optimize the choice of the learning in colleges 
and universities. And they may obtain more quantity and higher quality of institutional culture capital. For example, more poor students can choose their favorite schools and professions to learn, and can choose to continue their studies.

The funding that helps poor students gain cultural capital generally uses the economic status of the students' family as the main criteria. If one student's family was poor, he could apply for and obtain the appropriate funding.

\subsection{The Acquired Character of Human Capital Affects the Education Performances}

Compared to the physical capital, human capital is one capital form that acts as people's knowledge, skills, experiences and health. The significant symbol of human capital is that it belongs to one part of humans. "It belongs to humans, not only because it behaves in the human body, but also it is the sources of the future satisfaction or income." (Schultz, 1990a) Human capacities can be divided into congenital and acquired. As one "scarce resource", human capacities are mostly acquired through the efforts. We must make investment to get this "scarce resource". "The more money is invested in education, the more efficient labors will be got." (Schultz, 1990b)

Modern human capital of university students consists mainly in four areas: psychological quality, transferable vocational ability, professional competence and learning ability. Poor students have more disadvantages than non-poor students in the first three aspects. "Because of the long period of financially strapped status, poor students are prone to psychological problems such as low self-esteem, paranoia, loneliness and depression.” (Xiao \& Wang, 2013) Their psychological quality is always relatively lowly and weak. Students' transferable vocation abilities show in the following aspects: English level, using information technology and driving skills. Poor students share these hardware and data sources significantly less than non-poor students. Teachers in university normal classroom generally teach basic professional knowledge. More practices and training certifications would be needed to adapt to the enterprise professional requirements. Because of the shortage of economic capability and social capital, poor students would be restrained to enhance their professional competence. But through years of hard work and cultivation, poor students' overall learning abilities may be better than non-poor students. As long as given the opportunities, they might make up for shortcomings of human resources quickly. But such opportunities are often based on the sufficient economic basis, or linked to the economic activity meeting.

National scholarships, national motivational scholarships, and other scholarships are the affirmation of the students' comprehensive or learning abilities. They also can get some economic incentives. Poor students who get these awards through their efforts will acquire the respect of other students and teachers' recognition. It is the positive motivation to enhance self-confidence and improve psychological qualities. The bonus can be used to invest in the relevant trainings and certifications. Poor students who have the relevant certification and excellent performances will have more opportunities to participate in teachers' research and development teams, real projects and corporate internships to strengthen their professional capacities. Then, it will form a positive interaction between human capitals and educations.

\subsection{The Accumulation of Social Capital Affects the Educational Results}

The Chinese academics have no uniform definition about social capital. We generally use the Burt definition from the micro level perspective contacting with individuals. "Social capital refers to the contacting of the friends, colleagues, and other more. Through them, you get the opportunity to use capital (including other forms)...... It is the last one to determined whether success or not.” (Burt, 1995)

This definition can be understood as three meanings. Firstly, it is the relationship between one person with friends, colleagues, or other general contact. Secondly, it is the important factors to achieve specific goals. Thirdly, its function is based on the basic of culture and human capital. The education result is to cultivate excellent talented persons, and let them work on the suitable positions to maximize the positive effects in promoting social development and progress, and achieve their personal values. "Human being is the summation of all social relations." Educated person is also one part of social relations. Thus, social capital that has the interpersonal attribute can affect the educational results. The more social capital students accumulate, the more conducive it is to promote the optimization of educational results. On the contrary, it is not conducive to the educational results. 
Social capital obtaining mainly depends on social activities. Social capital of college students can be divided into the original part and the acquired part. It is decided by the subjects of different stages. The original part mainly inherits from social activities of the elder generation. The acquired part mainly obtains from social activities of the students themselves.

The original social capital of most poor students is less than non-poor students. "The acquired capital accumulations relates to the scope and effectiveness of individual social activities. Troubles of poor students' interpersonal relationship are more than non-poor students.” (Cai, 2006) Due to the limited economic capacity, poor students communicate in the small scope and the little time. It results in the small quantity and the little quality of social capital for poor students.

Social tuition assistance can help poor students expand their social contacts. Taking part-time jobs in campus can help poor students promote their communication with teachers, researchers and managers. Taking part-time jobs outside campus can help them contact various society officers. The persons who can provide part-time jobs always have the certain economic power or social status. Communicating with these persons can help poor students expand and promote the quantity and quality of their social capital.

\section{The Methods and Paths to Promote the Education Performances}

The funding promotes education performances through the positive effects of cultural capital, human capital and social capital. So we can hierarchically promote the education performances through the following three methods and paths: protecting the cultural capital to meet the needs of getting an education, upgrade human capital to meet the needs of self-development, gathering social capital to meet the needs of upward social mobility.

\subsection{Protecting the Cultural Capital to Meet the Needs of Getting an Education}

Tuition exemption and green channels perform better in our universities. It can basically solve the problems of poor students' coming into the schools to receive the education. It has relieved poor students' problems of living and learning with the gradually increasing yearly of the amount of national tuition assistance and the funding proportion of students. But it still needs to study and demonstrate on the funding amount and proportion. Otherwise, lazy behaviors would be cultivated in poor students because of too much free funding. And non-poor students would exclude poor students because of misunderstanding on the national policies.

The national student loans can be the major forms to guarantee poor students to get culture capital. "The state should formulate the relevant laws and regulations as soon as possible. It helps to regulate the rights and benefits of the lenders and borrowers, safeguard the positive atmosphere of student loans and form a positive circle.” (Shen, 2010) Meanwhile, in order to expand beneficial coverage, the amount of student loans should be increased further and the restriction should be relaxed. Applications and approvals of student loans should be regulated, and efficiencies of the staff at the grass roots level should be improved, particularly in remote underdeveloped areas. Universities should increase the publicity of student loans policy, and develop a good culture of student loans. At the same time, students should be encouraged to take responsibilities initiatively, and share responsibilities for the family and society, because responsibility sharing is the permanent solution which can promote the sustainable development of the society, families, schools and students.

\subsection{Upgrading Human Capital to Meet the Needs of Self-Development}

First, universities should establish special scholarships for poor students. Currently, scholarships that can identify the excellent students have not established special programs for poor students except national motivational scholarships. There are many funding paths for poor students, but there are few scholarships that are evaluated by students' economics and comprehensive qualities. So the beneficial coverage of scholarships is small for poor students. As previously mentioned, outstanding honors are the important motivations to promote human capital. Therefore, it is necessary to vigorously promote the evaluation of university scholarships especially for poor students.

The second is to carry out the project-oriented funding. According to the status of poor students' lacking in human capital, it should be correspondingly planned to promote human capital, supplemented with financial supporting and incentive, and operated in the project-oriented form. Through the monitoring to the access, process, and outcome of the projects, it can urge poor students to make up their insufficient and shorten the human 
capital gap. For example, universities and colleges can set up the practical innovation projects and professional skill certifications especially for poor students.

\subsection{Gathering Social Capital to Meet the Needs of Upward Social Mobility}

In recent years, development of social funding has reached a certain extent. But compared with the growth rate of higher education, there is still much room for improvement. Compared with the perfect social assistance system of the western countries, ours remains weak and powerless. First, in current situations, universities and colleges should take the initiative to attract the successful persons or enterprises to come into the donation processions by using their affections in the local areas. Government departments should provide the policy supports to encourage enterprises or individuals to donate for educations. While enjoying the social assistances, poor students themselves should try their best to improve culture capital and human capital, strengthen the connection with the donators and contribute to the community necessarily.

Secondly, when setting work-study jobs in the campus, universities and colleges could thoroughly take inherent advantages of talents to help poor students accumulate more extensive and high-quality social capital through arranging a certain number of "intellectual jobs", such as research assistance, manager assistance and entrepreneurship assistance, etc.

Thirdly, volunteer organizations should be composed mainly by poor students. Poor students cared by the state and society should contribute to the community and transfer the love. It is also the edification and growth. Meanwhile, it would push forward with the concentration of human capital for poor students because they acquired communication ability, problem-solving ability and good social benefits through voluntary activities.

\section{Acknowledgements}

This work was supported by the philosophy and social science fund project from Jiangsu Province Office of Education: "Research on Improving the Effectiveness of Ideological and Political Education by the Computer Persuasion Theory" (No. 2011SJB880111). And it was supported by the enterprise education emphasis project of Nantong University in 2013: "Research on the Mechanism and Practice of the Establishment of the Enterprise Culture in Universities".

\section{References}

Bourdieu (Y. M. Bao Translation) (1997). Cultural Capital and Social Alchemy. Shanghai: Shanghai People’s Publishing House.

Burt, R. (1995). Structural Holes: The Social Structure of Competition. Cambridge: Harvard University Press.

Cai, R. (2006). Research on the Interpersonal Communication of Poor Students (p. 49). M.D. Thesis, Wuhu City: Anhui Normal University.

Cao, Y., \& Li, P. (2010). Research on the Practice Path of the Education by Funding Under the New Funding Policies. Heilongjiang Higher Education Research, 10, 124-125.

People Net (2012). China has Established a Complete System of Student Financial Assistance Policy Covering all Stages of Education. http://edu.people.com.cn/n/2012/0831/c1053-18886945.html

Schultz, T. W. (B. Jiang, \& H. Zhang Translation) (1990a). Investment in Human Capital: The Role of Education and Research. Beijing: Commercial Press.

Schultz, T. W. (B. Jiang, \& H. Zhang Translation) (1990b). Investing in People: The Economics of Population Quality. Beijing: Huaxia Publishing House.

Shen, H. (2010). Review on Ten Years. Study of Student Loans in School of Education in HUST. Higher Education Research, 31, 65-73.

Wen, J. B. (2012). Government Work Report. http://news.xinhuanet.com/politics/2012lh/2012-03/15/c_111660147.htm

Xiao, J. G., \& Wang, L. R. (2013). Research on the Analysis of the Psychological Problems of College Students From Poor Families and Countermeasures of Ideological Education. Ideological Education Research, 2, 94-98.

Zhao, G. C. (2012). Research on the Mode Innovation of the Education by Funding in Colleges-Insist on Combining Supporting the Poor with Supporting the Spirit. Ideological Education Research, 8, 94-96. 